\title{
Gaps in genetic antidiscrimination law spur state action
}

Just over a year ago, advocates celebrated the signing of a landmark piece of legislation barring health insurers and employers from discriminating against people on the basis of their genetic information.

The Genetic Information Nondiscrimination Act (GINA), signed into law by US President George W. Bush on 21 May 2008, was the product of more than a decade of efforts to pass it on Capitol Hill. During those years, the sequencing of the human genome and an accompanying groundswell of genetic tests for diseases from breast cancer to Alzheimer's disease eventually pushed support for the legislation past the tipping point.

Now, experts are pointing out that GINA, for all it accomplished, left untouched several insurance markets that may be important for people contemplating getting genetic tests-or already holding the results of such tests. Longterm care insurance, disability insurance and life insurance are not addressed by GINA. This means that if, for instance, a 50-year-old individual has just learned that he or she carries a gene boosting the chances of developing Alzheimer's disease, there is nothing in federal law to prevent long-term care, disability or life insurers from refusing coverage on the basis of a positive test.
The issues raised aren't just theoretical. In 2005, Robert Green of Boston University and colleagues published a study of 148 people who received genetic tests indicating whether they were at increased risk for developing Alzheimer's disease (Health Aff. 24, 483-490; 2005). Those who were informed they had tested positive were, in the following year, nearly six times as likely to buy long-term care insurance as control subjects who didn't learn their test results.

"Serious disease has such an impact on families. And insurance products like life and long-term care are there, one hopes, to alleviate that impact. But in most states today you can be eliminated from the possibility of obtaining those simply because a disease with a known genetic basis runs in your family," says Susannah Baruch, a policy attorney with Generations Ahead, an Oakland, California-based nonprofit organization focused on genetic technologies.

Insurers say that Congress left life insurance and disability insurance out when they crafted GINA because they are fundamentally different from health insurance. 'Life insurers' ability to fully and fairly underwrite life insurance, disability income insurance and long-term care insurance is crucial to their ability to treat their existing and prospective customers fairly and to classify risks in a financially prudent manner,"

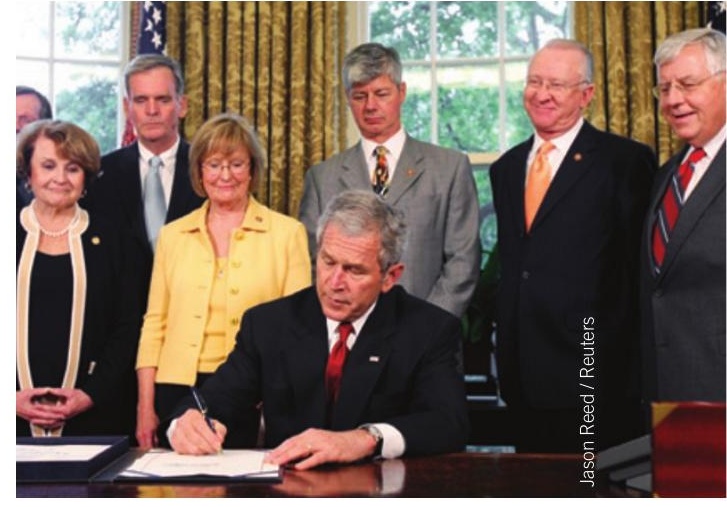

Partial coverage: Bush signs GINA into law

says Steven Brostoff, a spokesperson for the American Council of Life Insurers.

In the absence of a federal law, 16 states have adopted legislation addressing the use of genetic information in life insurance, 16 have done so for disability insurance and ten have tackled long-term care insurance.

"While GINA did lots of good things, there are other areas that have been left unattended," says Kathy Hudson, director of the Washington, DC-based Genetics and Public Policy Center of Johns Hopkins University.

Meredith Wadman, Washington, DC

\section{Production of radioactive isotopes proves problematic}

Australia's Open Pool Australian Lightwater (OPAL) research reactor has the potential to "make a real difference" in the effort to deal with the global shortage of radioactive isotopes used for medical research and testing, according to Michael Graham, president of the international Society of Nuclear Medicine.

Sustained global supply of medical isotopes is in long-term jeopardy as a result of problems with two reactors that have typically provided more than half the world's medical isotopes: Canada's Chalk River reactor and the Netherlands' Petten rector. Over half a century old, the Chalk River reactor closed temporarily in May due to a heavy-water leak-its third shutdown in two years. The reactor formerly supplied about a third of the world's molybdenum-99 (Mo-99), a uranium processing byproduct that many imaging procedures rely on.

In the Netherlands, the Petten reactor, which is nearly as old as its Chalk River counterpart, closed for maintenance in mid July. The Petten facility, which usually produces a third of the global supply of Mo-99, had raised its production by up to $50 \%$ to compensate for anticipated shortages, but it is scheduled to temporarily shut down for maintenance again in the first half of 2010.

During these closures, hospitals and research facilities have to rely on smaller reactors in France, Belgium and South Africa-all more than 40 years old-for Mo-99 supplies.

Procedures involving medical isotopes annually benefit more than 22 million patients in North America, 10 million in Europe and 14 million in the rest of the world.

A Society of Nuclear Medicine (SNM) task force identified the University of Missouri Research Reactor Center as the best possible source of a short-term boost to Mo-99 supplies. However, Graham, who in addition to leading the SNM also teaches radiology at the University of Iowa, says this would require a $\$ 50$ million investment.

"What pleases me is the level of collaboration internationally that is making it possible for us to get along," Graham says.
He said the current situation was caused by problems with old reactors and Canada's 2008 abandonment of two Multipurpose Applied Physics Lattice Experiment (MAPLE) reactors, which have experienced chronic problems since the first was commissioned in 2000 .

Although the MAPLE reactors were supposed to give Canada greater leadership in the global medical isotope market, Canadian Prime Minister Stephen Harper has resisted calls for them to be recommissioned, saying in June that Canada intends to cease medical isotope production.

The OPAL reactor in southern Sydney began operation two years ago and has recently been restarted after fuel management problems caused it to be shut down for almost a year. It is awaiting final approval from the Australian Radiation Protection and Nuclear Safety Authority to begin Mo-99 production. Graham estimates the OPAL reactor is capable of supplying about $10 \%$ of global Mo-99 demand.

Simon Grose, Canberra, Australia 